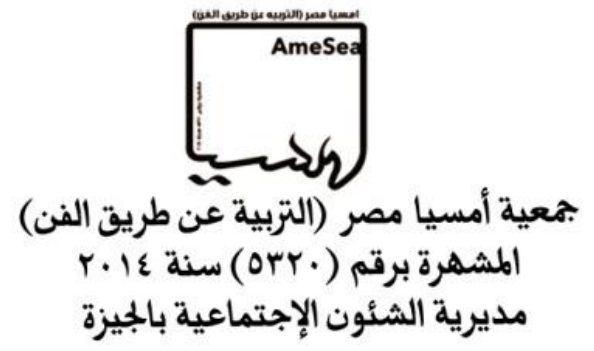

\title{
Education Through Digital Art About Art
}

\author{
Anders Marner \\ Umea University Sweden
}

Hans Ortegren

Umea University Sweden 
Each school was visited two to four times, and the art teachers answered questions about the use of digital media in relation to art history and paraphrases. Pupils preparing or already having accomplished work in this area, along with some pupils working with manual devices, were asked questions concerning the means, methods and points of view regarding their work.

\section{THEORY}

In a project running for three years, the authors have studied and reported on the use of digital devices in the subject of art in lower secondary schools in Sweden. This has also been linked to Swedish as a mother tongue and the subject of music. It has been concluded that four possible approaches to digital media can be identified.

The first mainly consists of attitudes of resistance to using digital media, arguing among other things about the insufficient space in the curriculum. Another approach that is quite common involves adding on some parts that can be done digitally, often having been tried out earlier on by teachers in special groups as a free choice. A third and less common position is an attitude of embedding digital media into the general conception of the content of the art subject. Theoretically, we also find a possible fourth position of changing the art subject so that it becomes totally digitalized and part of a general subject managing all kinds of new media under one umbrella.

The aesthetics of paraphrases is part of an ongoing chain of representations via representations. This is discussed in a dissertation presenting a theory of paraphrases in twentieth-century art (Örtegren 1992). It is stated that a paraphrase has an intertextual relation to the alluded work. With paraphrases of form, the main transformation deals with changes in the way a given subject is represented. With paraphrases of theme, the central transposition deals with representing the earlier subject in a new context. These two types basically refer to specific works of art. With the third type, paraphrases of style, the art refers to groups of works and uses common denominators such as artists or styles in order to comment on them. Art paraphrases tend to focus on the interplay between originality and imitation, both within contemporary art and between modernist and traditional concepts of art.

It has been stated that in the late modern and postmodern era paraphrases are becoming a genre of their own (Örtegren 1992). The connection between originality and the fear of influence are no longer in opposition.

Appropriation as used by Wertsch is linked to the possibility of using texts for one's own purposes and in new situations (1998). When the American artist Sherrie Levine used replicas of pieces of art in an installation, the art critic Douglas Crimp coined the term appropriation (1980). Both uses of the word appropriation contain a criticism of the modernist avant-garde myth of originality as something once and for all self-made and totally disconnected from any tradition. Connected to this is remixing (Erstad et al. 2007), as well as other ways of using multimodal strategies for visual renderings (Peppler 2010).

The researcher of media studies Lev Manovich proposes a new way of conceptualizing creativity that is linked to new digital media. If in the 1920 s it was believed that development was connected with avant-garde, today it is more connected to possible choices from large databases. Creativity lies within new selections and combinations, working from material that is chosen and not made from scratch (2002). The curator and art historian Nicolas Bourriaud 
uses terms like post-production concerning similar phenomena (2002). A typical example is a disc jockey who combines musical materials in playlists. The researcher in design theory Jan Michl uses the term re-design with respect to the way a designer stands in relation to earlier design (2002). This points to some kind of revival of the ideas before the modernist era when certain imitations of the old masters could be regarded as creative mastery and connected to originality (Örtegren 1992).

The world of art, just like art as a school subject, is still partly coloured by a modernist tradition. In some empirical studies it became evident that art teachers as well as their students had less respect for digitally constructed images than handmade ones (authors, in press). Accordingly, even if paraphrases in contemporary art tend to be an accepted form of art production, it seems clear that there are still other codes of evaluation within the art education sector among teachers and pupils.

Not surprisingly, priority competencies in the subject of art are often connected to a skill in crafts, linked to the Greek word techne, meaning technical skills. At the same time, the Latin ars is oriented more towards the qualities of style and expression within the work (Ortegren 1992). With the introduction of appropriation as an active category of relating to already produced works of art, this could be connected to a process of postproduction rather than merely reproduction.

\section{RESULTS}

Four somewhat different approaches to implementing digital media in the art subject were found during the field studies. At Hawthorn School, each pupil was supplied with a personal computer, but they were only occasionally used during art lessons. At Ash School, a set of PC 'nomads' was handed out to those pupils who needed them during the art lessons, and were quite regularly used by many students. A nomad is a trolley containing fifteen to twenty laptops.

At Pine School, six stationary computers were in use, and work was often carried out in projects involving small groups of pupils. At Alder School, two stationary computers were chiefly used, while extra computers and digital equipment were also available.

At Hawthorn School, the pupils were asked to make visual paraphrases as a special assignment and present them as a product made for and on the screen. Some other tasks were presented to the pupils with the intention of trying a free shareware program, to make perspective drawings or to work in a style using pointillism through a free-use program. According to the teachers, the result of this work did not address aesthetic qualities but was more about becoming familiar with a specific digital tool and thereby also understanding the way a specific mode within impressionism worked.

At Alder School, the pupils were asked to make a poster for a film, paraphrasing the stereotypes of gender attached to the characters or the plot. Most students chose to prepare a conventional drawing/painting, but a few sought to work digitally. The teacher said it was acceptable to draw from pictures but simple carbon copies were unacceptable. The point was that significant changes also had to be made so that some new content was added to the picture, changing the context. Pupils were also welcome to work digitally, and two boys took that opportunity. One of them asked his teacher while studying a picture on the Internet: 
I just must calculate (meaning carbon-copy) some items, may I do that?

I have to do it by hand cos I can't manage Photoshop.

When asking the teacher about ways of looking at the possibilities and prohibitions on copying, some similarities and differences concerning digitally made copies and manually drawn copies became apparent. In the digital programs 'copy and paste' was the way to proceed, and the aim was still to choose how to put in or take away, how to combine and manipulate existing pictures. This was sometimes a good way to help those pupils who lacked an interest in or knowledge of how to render a likeness by using traditional tools such as pen or pencil.

A 'pass' was awarded if they could present a picture that they had somehow edited and altered. It could also give these pupils self-esteem and inspire them to carry on and find new ways of combining traditional drawing and digital images.

Similar considerations were made by the teacher concerning the pupils' possibilities to copy using carbon paper. Even if the pupils were asked not to, it could be accepted as a means to an end of learning how to make drawings without copying. It was still quite apparent that making pictures that were largely directly based on copies was valued less by both the teacher and the pupils.

At Ash School, some possible projects were presented simultaneously and the pupils could choose to make visual paraphrases with or without computer assistance. Most other options were presented in a similar way, with an emphasis on possible presentations also made through the computer or put on a screen so that they could be shown outside the classroom. At Pine School, the pupils were given assignments with possibilities to choose from and to invent their own tasks within certain limits. On occasion most pupils were connected to an external project that had started in cooperation with two teachers and linked to projects with partners, including from environments outside the school.

In most of the observed cases the pupils chose works of art to be paraphrased with some guidance from their teachers. The next step was to propose significant changes by adding and withdrawing elements from the selected and digitally copied work of art.

We have chosen an example of one boy in 9th grade in Ash School. According to his teacher, he did not have a good idea of what to do for an assignment, but the teacher knew he was interested in cars, especially American classic ones. On the Internet he found one of his favourites and printed it on paper. The next step was to outline the contour lines, and then scan it for use on a computer.

In this phase, the teacher and the pupil discussed what type of art could be linked to American cars from this era. After searching among American art, the student soon developed an interest in making a connection to pop art and pictures of Andy Warhol were actualized. During this process, the student lifted parts of Warhol's Campbell's Soup Cans to place on different areas of the car.

When interviewing the pupil it became apparent that he was very focused on his task, but he had great problems coming to grips with the paint program to fill in the areas according to his original vision. All in all, he was proud with the result so far and did not expect to be able to make a corresponding picture by traditional means using pen and pencil. The teacher mentioned this work as an example of something that had moved far beyond the pupil's earlier 


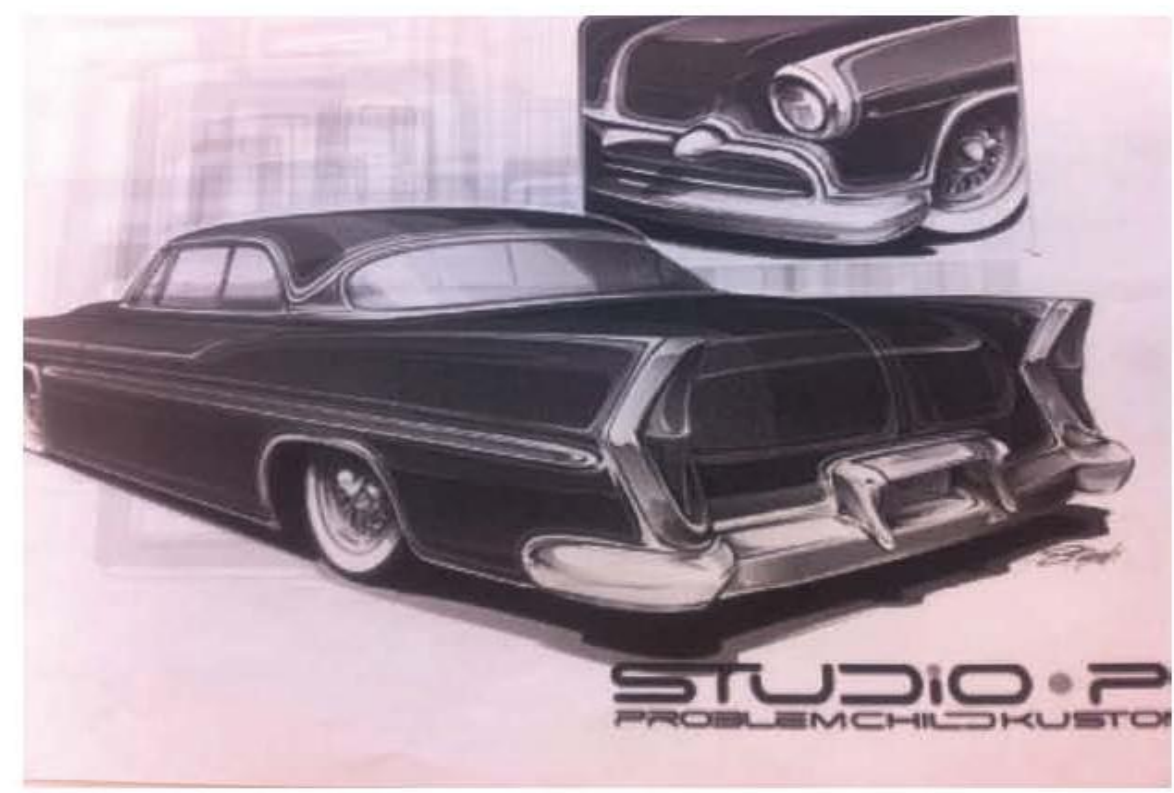

Figure 1: American car from the Internet (Ash School).

works. According to his teacher, it would not have been possible to manually prepare such a good work had he not worked digitally. The teacher referred to both the creative inputs during the process and to the finish of the work

The next example also comes from Ash School where a girl had picked out the famous Swedish picture The Gate-Coin as something to paraphrase.

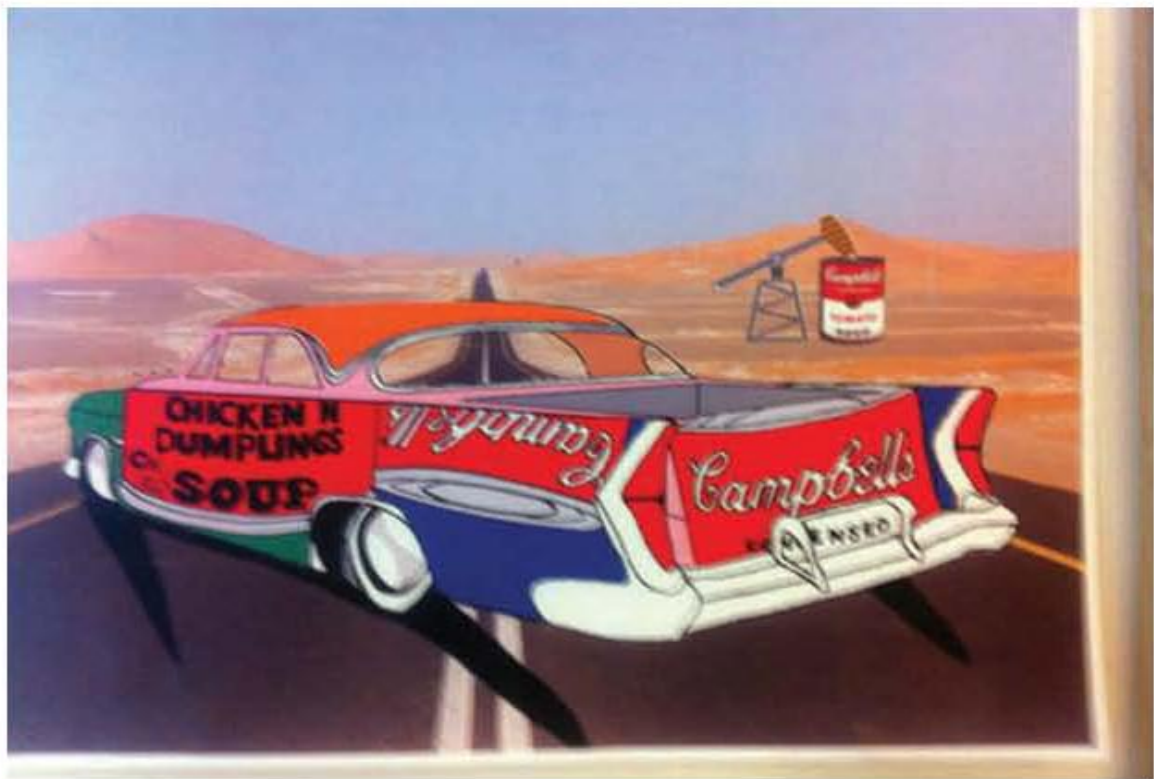

Figure 2: Combining elements from Andy Warhol (Ash School). 


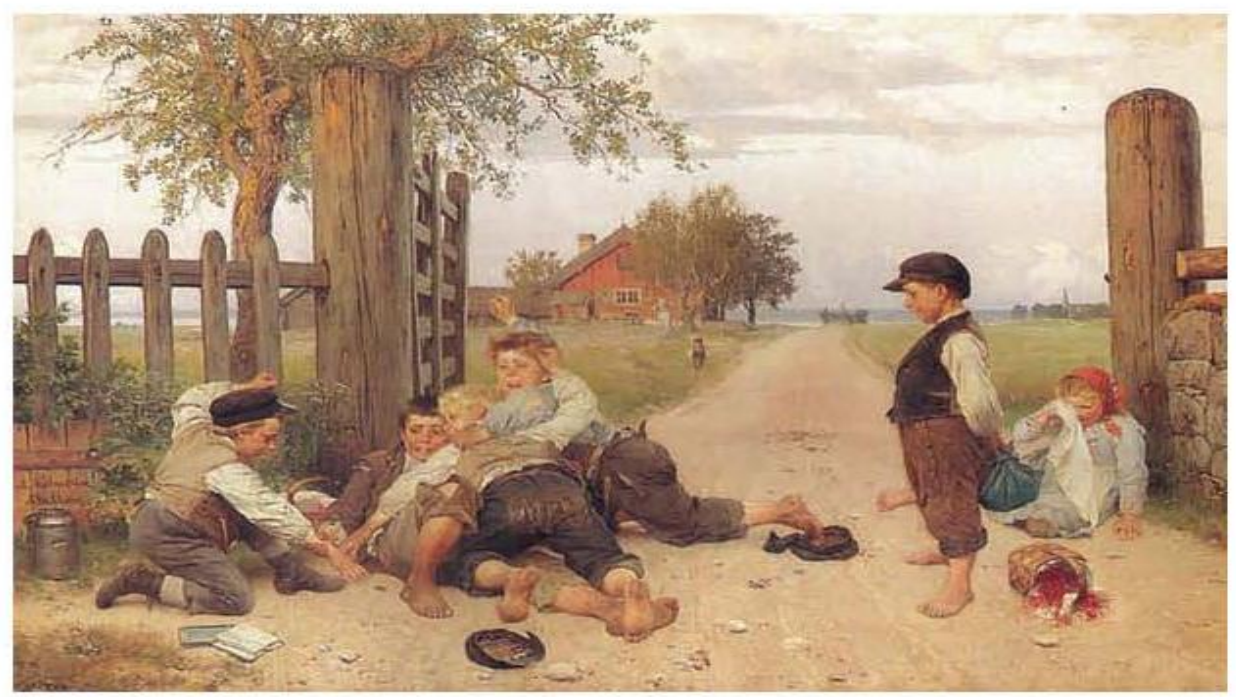

Figure 3: August Malmström: Grindslanten, The Gate-Coin (1885).

As she read about it on Wikipedia she realized it had been made in an area of the capital that these days is a typical suburb with skyscrapers and a large ethnic diversity. She therefore decided to use her own surroundings and friends to reflect the story of fighting over money tossed on the ground in a similar environment. In this case, the theme was reconstructed as a 'living picture' and photographed. According to the interviewed girl, the next step was to write about the picture and analyse it in connection to the original.

This is a good example of where the concept that relates to contrasting circumstances makes it extra interesting. Without the background knowledge,

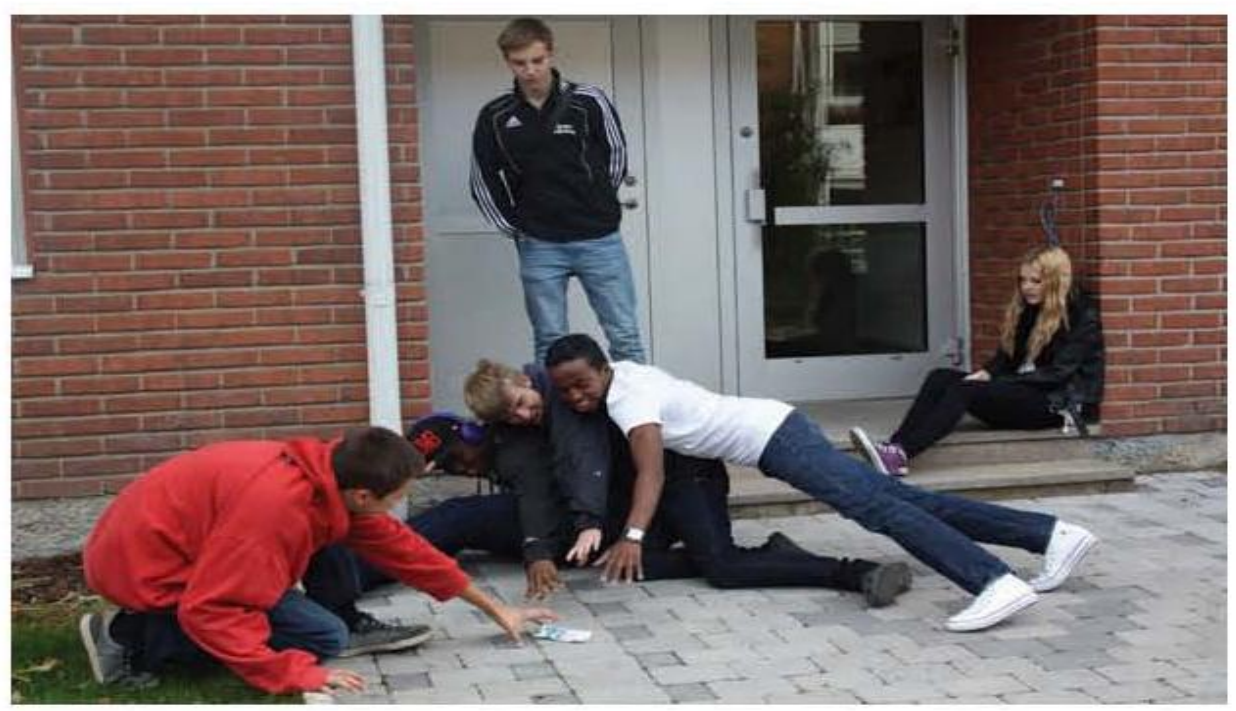

Figure 4: August Malmström: The Gate-Coin, reconstructed today (Ash School). 
the picture would not tell such a fascinating story and without introducing an interesting way of staging the story pictorially the effect would be smaller.

Both the teachers and pupils show some ambivalence concerning the assessments of digitally made pictures. Some pupils declared that pictures drawn by hand reveal far more knowledge of the art subject than reusing and combining digital images for one's own purposes. Yet other pupils claimed that mastering digital image programs takes a lot of effort and is worth good grades.

The teachers express similar opinions, declaring that it is important to be sure of knowing how to examine the different layers and thus knowing the active part of the pupils when creating a picture by using other pictures as a point of departure. In the interviews, two teachers also stated that, by letting the students complete some tasks by only showing them on their laptop screens, this allows possibilities to let pupils present their process directly to their teacher, bringing in the qualities of communicating about the devices used in comparison to traditional presentations on the classroom wall.

One teacher also made great use of the technical possibilities of showing pupils' works in public places within the school, as well as on the school website. This way of showing work is also strongly exemplified by the works shown on school websites by the two other schools and their teachers. Observations also revealed that it was quite common for pupils to search for ideas via Internet search sites as Google, and specifically when connected to tasks like paraphrasing a work of art.

At Pine School, the teachers' general strategy was to enable the pupils to work across different subjects, and to carry out projects specified by students alone or in groups. This method often led to combinations of imagery connected to digital media and performed within that area, as well as combinations with traditional media, or made only by hand. In this school, the pupils (and their teacher) more often took it for granted that the medium to work with derived from the ideas they wanted to visualize.

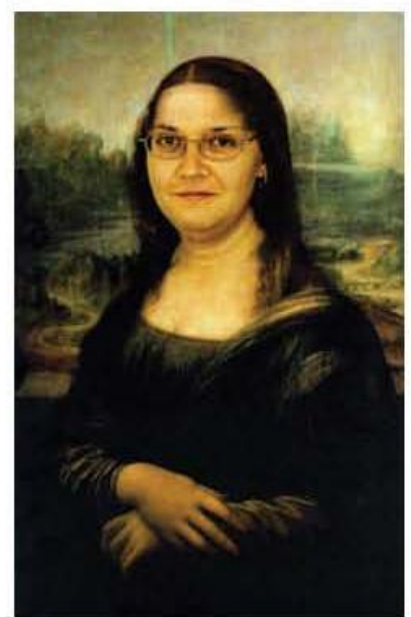

Figure 5: Pine School - digital paraphrase of theme.

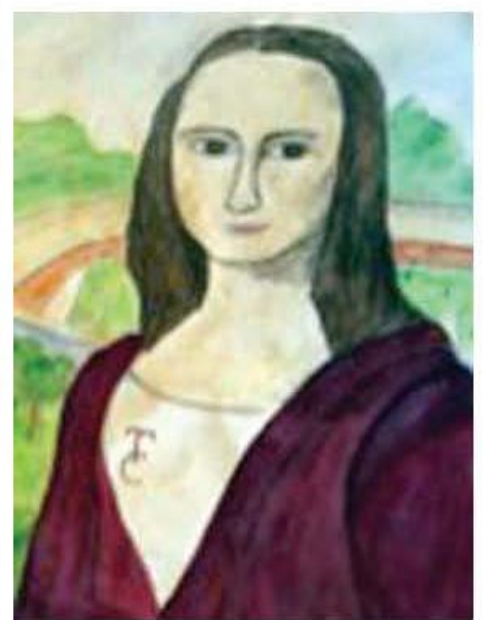

Figure 6: Manual paraphrase of theme.
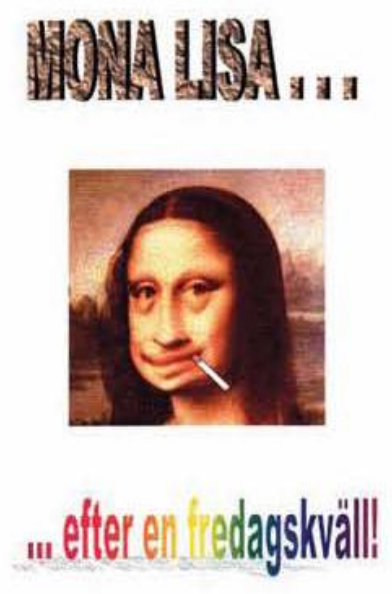

Figure 7: Paraphrase of theme. Text: Mona Lisa after a Friday night (Pine School). 
This specific study deals with student work using art history as a point of departure for making visual paraphrases. This is quite a common task for pupils in Grades 8 and 9, but so far it is quite rare for the tasks to be mainly carried out using digital tools. When linking the observations related to this case study with other studies about more general conceptions and practices of digital image making, some important connections become apparent.

Even when teachers suggest that pupils may work mainly digitally, there are instances and incidents that can be treated as resistance to digital media. For one thing, it can be related to a lack of reliance on and doubts about the importance of digital media knowledge as an indication of valuable knowhow, from both the side of the teacher and the pupils themselves.

The practice of adding on digital media on certain limited occasions and for special purposes is more frequent. Within this pedagogy, some examples are found in connection to visual paraphrases. An eye-opener for the teachers seems to be that the new tools also allow fresh possibilities for presenting the completed pictures. It also became apparent to the teachers and pupils that such pictures could occasionally be shown on sites selected by the teachers through school webpages to attract parents and other students.

Using visual paraphrases as one of many possibilities in an embedded way throughout art lessons is a concept that was primarily carried out in the Pine School. This involves an ambition not to specify certain assignments, but to let the pupils themselves plan their own projects, having digital images as an equal option alongside traditionally handmade ones.

The connections between 'made by yourself' and 'handmade' are still quite strong among the pupils in general. A more sophisticated view of the possibilities of digital appropriations being original work on the same premises is not in place. Still, there is evidence that once pictures are digitally produced, with a lot of effort and when solutions to emerging problems are at hand, it is accepted and regarded as important work by both the pupils and their teachers. All in all, the experience of these types of appropriations is relatively uncommon, and the assessment criteria still need to be further elaborated in practice. The use of digital media within art holds strong potential for opening up pupils' possibilities to create their own pictures that they can master and can feel proud of. This demonstrates that possible ways of using imitation as an important step towards original creations can be explored when using digital media.

\section{SUMMARY}

According to the collected data, it is most common that the pupils start off by making slight changes to a digitally reproduced work of art, predominantly making paraphrases of theme. It is often the case that an offer is made to do this for those who so desire, but making paraphrases is still rarely undertaken by the vast majority and, when it is done, it is more to train skills in using certain software.

The teachers mentioned the special circumstances that give room for pupils to explore new possibilities to make pictures without needing to have manual technical skills. They also noted that pupils who do have these skills often also use the traditional methods to a large degree. Most of the interviewed pupils expressed mixed feelings about the quality of making pictures digitally in comparison with traditional painting or drawing. The idea that originality is connected to making everything from scratch and by oneself is still valid, and impacts on the belief that this can be done using digital devices. 


\section{DISCUSSION}

New media can attract more participatory fans because they are not pressured by a certain canon. People are tending to become more involved in new digital media, like reality soaps, communities and social media, commenting and being part of a new collective intelligence concerning specific TV series, etc. One strives to become both a producer and a consumer, a prosument (Jenkins 2006). This is connected to what is called remixing (Erstad et al. 2007), a highly valued practice that enables engagement in a participatory culture that is required to be considered literate today. In a study quoted by Peppler (2010), professional media artists who were evaluating works by children were unsure how to position the works, partly because it was distant from some values within the art community. In contrast, Peppler concludes that "The arts classroom could potentially be the site for more critical reflection [...] moving youth from creating work that simply emulates existing media to using references to put forth a message' (2010: 2142). There seems to be no need to simply copy a picture digitally because that would mean no changes have been made. If, on the other hand, one uses a lot of effort to faithfully copy a picture by hand the success in copying might be valued. However, it would still not be valued as an artistic practice. But it is somewhat different when you elaborate by combining pictures, constructing a new picture that has been melded together through a post-production process of remixing several pictures.

Turning to the three types of paraphrases (Ortegren 1992), the way to consider if a work holds the potential of originality varies slightly depending on what kind of paraphrase is at stake. A critical distance is needed to show an agenda for use of the referred work, as well as for the potential messages that can be found in interpretations of the new work.

In paraphrases of form, the digital manipulation must be executed so that a link is established between the formal expression localized in the paraphrased work and the formal expression put forward in the commenting work. This presupposes substantial reconstructions made with digital applications.

In paraphrases of theme, the earlier work must be put in a new context, actualizing it or using it to present a new visual connection that justifies the remix. In paraphrases involving The Scream by Edvard Munch (1892), an unnamed artist on the Internet has made a pun juxtaposing a famous picture of Marilyn Monroe seemingly afraid of showing too much with the much more breath-taking theme referred to by Munch. In another picture made using crayon by a girl one year after 11 September 2001, the theme is connected to the horrifying deaths caused by the terrorist acts on the twin tower buildings. Both pictures need to be executed artistically to find a good way to simulate the expressionism of Munch, but with different means (Figure 8).

In paraphrases of style, it would not be sufficient to make a picture that looks like, for instance, a typical impressionistic, surrealist or expressionistic work of art. Of course, succeeding in this work by emulation in the traditional style is a good indicator of an ability to copy styles of works of art. To do so, one must identify the characteristics of the styles and be able to render them in an own work. Correspondingly, when using digital pictorial media, one would have to put the elements together to form a whole so that they merge into a rendering of a chosen category of artworks. But a critical distance would still be needed, pointing out certain significant differences in comparison to the styles referred to. 


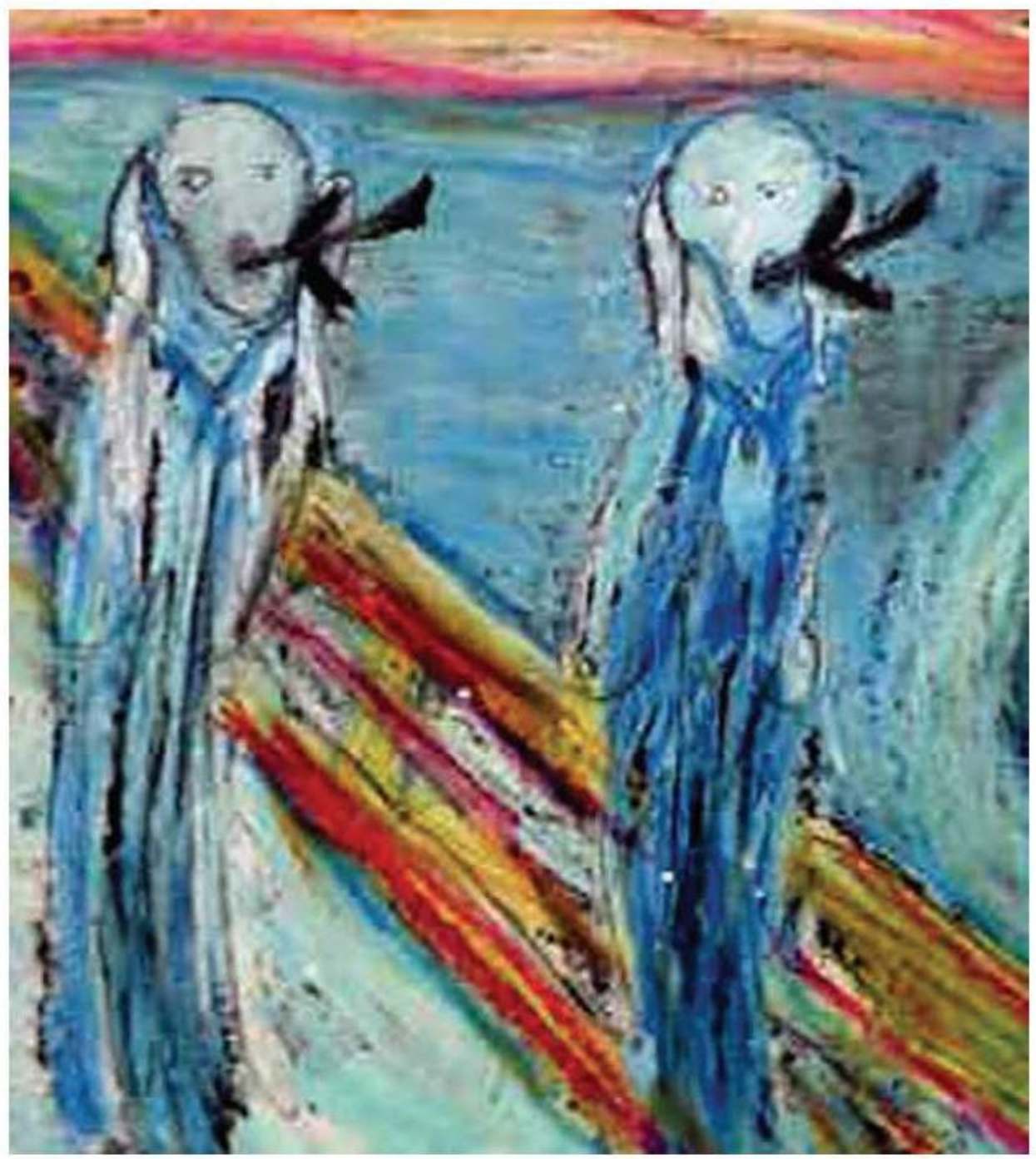

Figure 8: Handmade paraphrase combining Munch's The Scream with the Twin Towers (Pine School, 2002).

The point is that the digital use of images does not per se need to be made from scratch; instead, one has to be able to see them as elements of departure for further elaborations. Namely, the handicraft of assembling digital images differs somewhat from the skill of drawing or painting. The final result can of course, and often does, consist of a mixture of digital and manual work. But whichever methods are used, how the originality and critical power can be traced within the works is important when assessing the products as to whether they will be considered more than attempts to make emulations or copies of other works.

It may be expected that the more digital visual media are offered as a way of making pictures within the subject of art in school contexts, the more the 
traditional modernistic ways of totally contrasting originality with imitation will be called into question.

It was once believed that in order to be able to make something really original, you first must be able to match the traditions and be skilled in the basics required within a certain canon. While this might still be true in many respects, it is now challenged by digital competence that is measured somewhat differently. The rendering of traditional pictures and genres may not have to be duplicated manually any longer. Nevertheless, being observant regarding the underlying elements, schemes, compositions and structure that underpin pictures and styles becomes even more important for doing original remixes and post-productions of interest. Remixes and post-productions constitute genres of their own where the capacity to use digital tools both limits and opens up new possible pictorial worlds.

When it comes to the use of different categories of paraphrasing, it seems obvious that thematic paraphrases are generally the most frequent. This has to do with the fact that pupils usually start off with a digital copy of a specific work of art and then make certain juxtapositions, additions or removals in order to put it in a new context. The case of using La Gioconda/Mona Lisa, turning it into a self-portrait or a playful comment, is a typical example. Working with this method is not so technically demanding and both pupils and their teachers are a little (Figure 6) sceptical about assessing the outcomes highly if the elaboration is done with 'copy-paste', in just one or two layers. Still, the fact that it is visually impressive raises self-confidence, in particular among pupils with low expectations of their ability to 'make their own pictures'.

When comparing paraphrases of theme made digitally with manual methods, the latter are judged in relation to the ability to render the original. In one case (as in the example of The Scream by Edward Munch), this ability to use crayons to accentuate the expressionistic style, paired with the concept of a double image to connect to the destruction of the Twin Towers, leads to a very strong picture. In a similar sense, the digitally reconstructed Marilyn Monroe fits into the digital copy of Munch's picture, something that makes it merge in well, and reveals quality.

In the case of paraphrases of style (Figures 2-4), the final result is very impressive according to the teacher, bearing in mind that the boy had very rarely made any pictures of quality by hand. The boy started off with a copy of a picture of a car, but had to rebuild it by adding other colours and to finally place it in a background that was fitting and made sense. Such digital processing is not very far away from a corresponding manual approach when composing a picture step by step. It could well be a good point to make use of digital imagery to make pictures from the start, mastering the digital tools to give new forms to historically known pictures. Possibly the toolboxes, the costs of using them and the ability to create with digital imagery will lead to a new and more widespread generation of picture-makers through art education.

The three areas mentioned as general guidelines of overall interest within school curricula in Sweden are personal development, democratic citizenship and abilities to be prepared for further studies and occupations. When looking at the digital products making paraphrases, a common denominator is that the pupils are asked to present a personal point of view on the paraphrased work/works. With paraphrases of theme, this often leads to a comment from today's perspective, involving the telling of a story rather than simply showing or storing interesting pictures that others have made. 
When teachers strive to let digital media become an embedded tool (Marner and Örtegren 2013) in the palette of art education, it is likely that the learning outcomes of using these tools lead to appropriation rather than stop at an elementary mastering of the use of certain instrumental techniques. This can be exemplified by Figures 4 and 8 . This is not as such connected to either digital or manual tools but to a deeper conception of the subject.

With paraphrases of style, finding out more about the style that is to be commented on also demands an insight into digital tools to break down and rebuild images. This would also be the case with paraphrases of form that were not exemplified in this study. Presumably, such pictures will be made by pupils when they come to terms with digital tools to such an extent that they can use them in a similar way as the ordinary pens, pencils and cameras these tools are developed from! In order to carry out 'genuine' post-production, the teachers and their pupils will certainly develop new methods by using new means to master appropriations as defined by Wertsch (1998), perhaps adding that they will be used for genuine own purposes and carefully selected new situations! One way to become aware of this process is to further develop instruments for formative evaluation, as observed in a general context by Hattie (2009). Such a focus remains to be placed in media-specific contexts as done, for example, by Hanna Kaihovirta-Rosvik in her dissertation Images of Imagination-An Aesthetic Approach to Education (2009).

\section{REFERENCES}

Bourriaud, Nicólas (2002), Postproduction. Culture as Screenplay. How Art Reprograms the World, New York: Lukas \& Sternberg.

Crimp, Douglas (1980), 'The photographic activity of postmodernism', October, 15 (Winter, 1980), pp. 91-101.

Erstad, Ola, Gilje, Øystein. \& de Lange, Thomas (2007), 'Re-mixing Multimodal Resources: Multiliteracies and Digital Production in Norwegian Media Education', Learning, Media and Technology (electronic version), 32:2, June, pp. 183-98, http://www.tandfonline.com/doi/abs/10.1080/1743988070134 3394\#preview, (2013-10-23).

Jenkins, Henry (2006), Conoergence Culture: Where Old and New Media Collide, New York: New York University Press.

Hattie, John (2009), Visible Leaming, New York: Routledge.

John, Peter (2005), 'The sacred and the profane: Subject sub-culture, pedagogical practice and teachers' perceptions of the classroom uses of ICT', Educational Review, 57: 4, November, pp. 467-488.

Kaihovirta-Rosvik, Hanna (2009), Images of Imagination-An Aesthetic Approach to Education, dissertation, Åbo: Åbo University Press.

Manovich, Lev (2002), 'Who is the author? Sampling/remixing/open source', http://www.manovich.net/texts, 2013-10-23.

Marner, Anders, Ortegren, Hans (2013), 'Four approaches to implementing digital media in art education', Education Inquiry, 4: 4, December 2013, pp. 1-18. http:/www.education-inquiry.net/index.php/edui/article/ view/23217/0.

Michl, Jan (2002), 'On seeing design as redesign: An exploration of a neglected problem in design education', http://www.designaddict.com/essais/ michl.html. Accessed 23 October 2013.

Örtegren, Hans (1992), 'Konst med konst som motiv'/Art with art as a motive', dissertation, Umeå: Umeå University. 
Peppler, Kylie A. (2010), 'Media arts: Arts education for a digital age', Teachers College Record, 112: 8, pp. 2118-53.

Skolverket (2011), Läroplan för grundskolan, förskoleklassen och fritidshemmet/ grundskolan Lgr 11, Bild/Curriculum for compulsory school, the pre-school class and leisure-time centre Lgr 11 Art, http://www.skolverket.se/om-skolverket/ publicerat/visa-enskild-publikation?_xurl_=http $\% 3 \mathrm{~A} \% 2 \mathrm{~F} \% 2 \mathrm{Fwww5}$.skolverket.se $\% 2$ Fwtpub\% 2 Fws $\% 2$ Fskolbok $\% 2$ Fwpubext $\% 2$ Ftrycksak $\% 2$ FRec ord\%3Fk\%3D2575. Accessed 23 October 2013.

Wertsch, James V. (1998), Mind as Action, New York Oxford: Oxford University Press.

\section{SUGGESTED CITATION}

Marner, A. and Örtegren, H. (2014), 'Education through digital art about art', International Journal of Education through Art 10: 1, pp. 41-54, doi: 10.1386/ eta.10.1.41_1

\section{CONTRIBUTOR DETAILS}

Anders Marner is Professor at the Department of Creative Studies, Umea University, Sweden, where teachers in Art, Music and Sløjd are educated. He has an Art teacher exam from University College of Arts, Craft and Design in Stockholm and has worked as an Art teacher for several years. He became Ph.D. in Art History 2000, and has been teaching and researching with a focus on sociocultural theory, semiotics and the school subject Art, within the research subject Pedagogical Work.

Contact: Dept. of Creative Studies, Lärarutbildningshuset, Umeå University, SE-901 87 Umeå, Sweden.

E-mail: anders.marner@estet.umu.se

Hans Ortegren (assistant professor) is an art teacher and a Ph.D. in art history (1993) about paraphrases in twentieth-century art. Pedagogy in the art and abilities to represent it in acts of comunication by visual means through semiotics is a mayor concern. I am a part of the project School Subject Paradigm and Teaching Practice in the Screen Culture - Art, Music and Swedish. I also work with The National Eoaluation of Art in Swedish Compulsory School (2011-2014).

Contact: Dept. of Creative Studies, Lärarutbildningshuset, Umeå University, SE-901 87 Umeå, Sweden.

E-mail: hans.ortegren@estet.umu.se

Anders Marner and Hans Ortegren have asserted their right under the Copyright, Designs and Patents Act, 1988, to be identified as the authors of this work in the format that was submitted to Intellect Ltd. 
Four schools' environments have been selected where paraphrases in art is a common denominator as a choice during secondary school. In this study, comparisons are made between digitally produced paraphrases, hand made paraphrases and blended production. The purpose is to shed some light on how the attitudes towards appropriations can be related to different media-specific tools. Theories about quotations in art are used to commenting on student's work when paraphrasing by means of digital and/or manual techniques. The concluding remarks are that digital paraphrases of theme dominates, using quite simple juxtapositions, but still with interesting implications. Different ways of working with pictures digitally exposes multimodal ways for pupils to appropriating picture-making for their own purposes.

\section{ABSTRAKT}

\section{NYCKELORD}

Fyra skolmiljöer har valts ut där elever gjort parafraser på konstverk som uppgift $i$ bildunderoisningen. I den här studien jämförs arbeten som gjorts för hand (analogt) med sådana där digitala verktyg också använts. Syftet är att belysa hur inställnDigitala medier ing till approprieringar kan variera beroende på vilka mediespecifika verktyg som Parafraser anoänts vid bildproduktionen. Teorier om parafraser inom bildkonst brukas for att kommentera elevernas tilloägagpångssätt vid parafrasering med digitala och/eller analoga tekniker. Konklusioner är att tematiska parafraser dominerar, där relatiot

digital media paraphrases secondary school 